\section{Advanced ultrasound for prenatal interventions}

\author{
Katika Nawapun, Nisarat Phithakwatchara, Suparat Jaingam, Sommai Viboonchart, \\ Nadda Mongkolchat, Tuangsit Wataganara
}

Division of Maternal-Fetal Medicine, Department of Obstetrics and Gynecology, Faculty of Medicine, Siriraj Hospital, Bangkok, Thailand

Ultrasound is an integral part of prenatal interventions. Doppler studies and 3-dimensional ultrasound (3DUS) are frequently used to determine whether fetal surgery is required. The operator's experience remains crucial for reducing procedure-related morbidity. Real-time 3DUS (or 4DUS) can simultaneously display the needle tip in three orthogonal planes, providing reassurance that no fetal parts are in the path. In experienced hands, 4DUS guidance may not be more effective than B-mode, but its value for less-experienced operators remains to be determined. Recent developments in needle, shunt, and video endoscopic technologies may compliment the use of image-guided in utero procedures. Future developments of higherdimensional transducers and image software may improve the utility of ultrasound for invasive obstetric interventions.

Keywords: Fetus; Ultrasonography; Surgery; Shunt; Endoscopy

\section{Introduction}

In addition to diagnosing major malformations and ruling out additional anomalies in fetuses, high-quality (level II) prenatal ultrasound is also used to assess the severity of conditions so that management options can be individualized [1]. Because ultrasound is relatively inexpensive, portable, and safe, and because it provides real-time images, it has been used as a major tool not only for prenatal diagnostic purposes, but also for interventional purposes. The potential benefits of prenatal interventions need to be balanced with the risks of procedure-related maternal and fetal complications. Brightness-mode (B-mode) or 2-dimensional ultrasound (2DUS) is routinely used for real-time image guidance of the needle during prenatal diagnostic procedures (i.e., chorionic villus sampling [CVS], genetic amniocentesis, and percutaneous umbilical blood sampling). This allows for the development of skills that support more complex in utero interventions. Direct fetal access was traditionally achieved via open hysterotomy (so-called open fetal surgery), which was associated with higher maternal morbidity and an increased risk of premature birth due to its invasiveness. Less-invasive fetal access is also possible with smaller instruments (i.e., needles, shunts, and fetoscopes) guided by real-time ultrasound. The significant technical progress reported in recent years has improved the perinatal outcomes of minimally invasive procedures, for which ultrasound is indispensable. This article aims to present a dedicated, but not systematic, literature review of recently

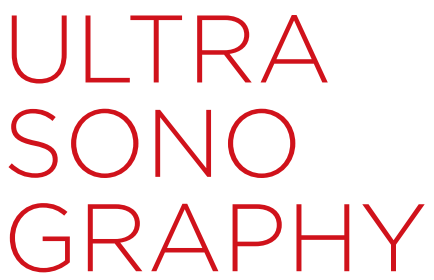

\section{REVIEW ARTICLE}

https://doi.org/10.14366/usg. 18011 pISSN: 2288-5919 - elSSN: 2288-5943 Ultrasonography 2018;37:200-210

Received: March 13, 2018

Revised: May 2, 2018

Accepted: May 2, 2018

Correspondence to:

Tuangsit Wataganara, MD, Division of Maternal-Fetal Medicine, Department of Obstetrics and Gynecology, Faculty of Medicine, Siriraj Hospital, 2 Prannok Road, Bangkoknoi, Bangkok 10700, Thailand

Tel. +66-11-662-419-7000

Fax. +66-11-662-418-2662

E-mail: twataganara@yahoo.com

This is an Open Access article distributed under the terms of the Creative Commons Attribution NonCommercial License (http://creativecommons.org/ licenses/by-nc/3.0/) which permits unrestricted noncommercial use distribution, and reproduction in any medium, provided the original work is properly cited.

Copyright @ 2018 Korean Society of Ultrasound in Medicine (KSUM)

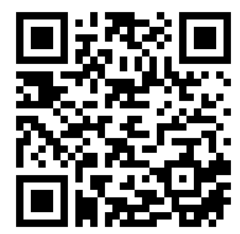

How to cite this article:

Nawapun K, Phithakwatchara N, Jaingam S, Viboonchart S, Mongkolchat N, Wataganara T. Advanced ultrasound for prenatal interventions. Ultrasonography. 2018 Jul;37(3):200210. 
developed sonographic techniques and their accessories related to in utero interventions.

\section{Advances in Prenatal Ultrasound for Diagnosis and Prognostication}

Once an abnormality is suspected based on a prenatal ultrasound examination, it should be confirmed by an experienced practitioner or through a team approach. Doppler studies and 3-dimensional ultrasound (3DUS) are frequently used to determine whether fetal surgery is a viable option. In utero surgery is now routinely offered at fetal medicine centers across the world. Twin-to-twin transfusion syndrome (TTTS) is a common indication for prenatal surgery. It is a serious complication of monochorionic twins as a result of unbalanced blood circulation due to vascular anastomoses in the placenta shared between the twin fetuses. These pathologic anastomoses on the chorionic surface can be photocoagulated under direct visualization with miniaturized video endoscopy (fetoscopy). Alternatively, chorionic vasculature and anastomoses can be mapped non-invasively with a 3DUS sonoangiogram, as demonstrated in Figs. 1 and 2. Three-dimensional sonoangiography has been reportedly used to assess the complex circulation shared between conjoined twins $[2,3]$. Another rare and severe complication



Fig. 1. Three-dimensional sonoangiogram of a deep arteriovenous chorionic anastomosis (arrow). This was a case of monochorionic diamniotic twins at 20 weeks of gestation with twin-to-twin transfusion syndrome. The deep arteriovenous chorionic anastomosis is an abnormal blood vessel connection that forms in the placenta and allows blood to flow unevenly between the fetuses. of monochorionicity is the twins reversed arterial perfusion (TRAP) sequence, which occurs when the heart of a normal-appearing

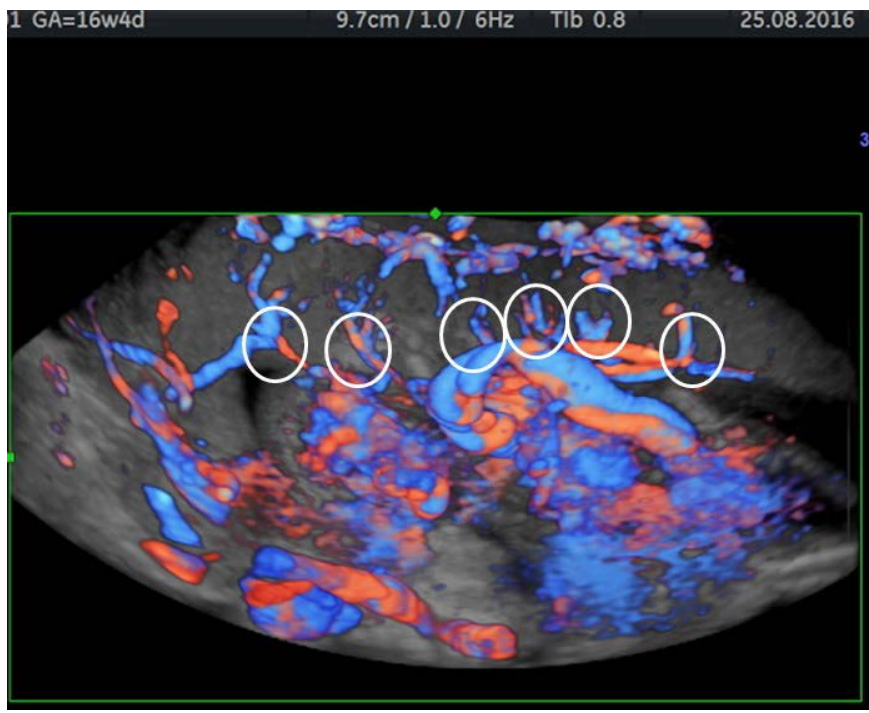

Fig. 2. Three-dimensional sonoangiogram of multiple deep arteriovenous chorionic anastomoses along the vascular equator. This was a case of monochorionic diamniotic twins at 16 weeks of gestation with twin-to-twin transfusion syndrome. The deep arteriovenous chorionic anastomoses (circled) cause an intrauterine blood transfusion from one twin (donor) to another twin (recipient).

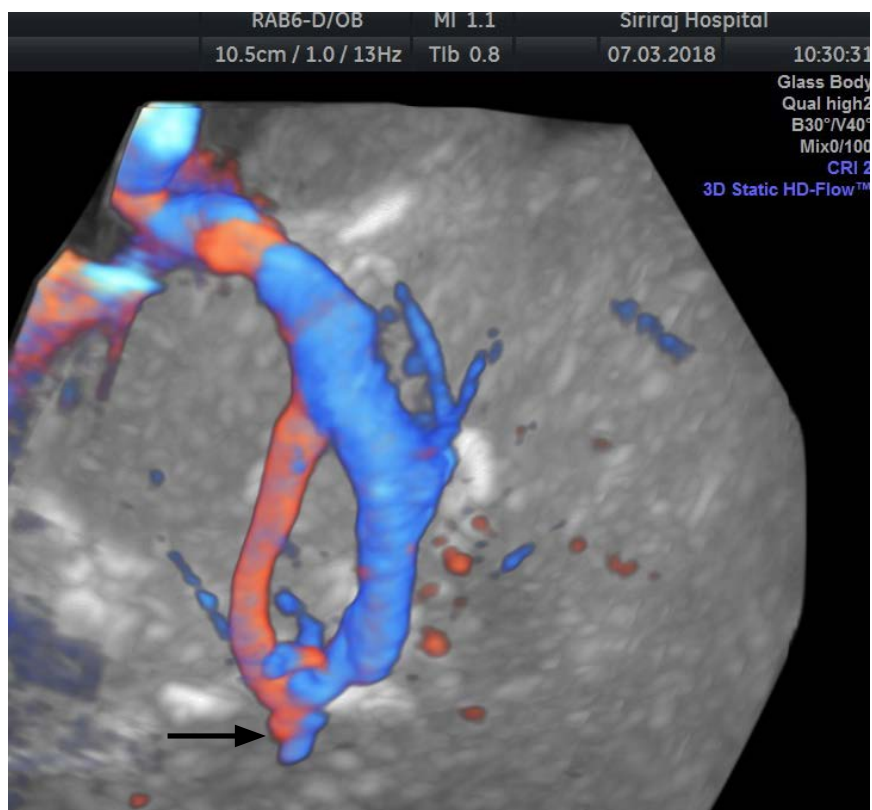

Fig. 3. Three-dimensional sonoangiogram of arteriovenous shunting inside the acardiac fetus (arrow). This was a case of monochorionic twins at 24 weeks of gestation with twins reversed arterial perfusion sequence. In this condition, the acardiac twin acts a parasite, putting the pump fetus at risk of high-output cardiac failure. 
twin serves as the pump for an acardiac twin. The ever-present arteriovenous shunting in the acardiac fetus can be demonstrated with 3D sonoangiography (Fig. 3). The high mortality of 50\%-75\% in the pump twin is the result of high-output cardiac failure and hydrops [4]. Umbilical cord entanglement in monoamniotic twins can also be visualized with a 3D sonoangiogram, as shown in Fig. 4.

Despite improvements in perinatal care, significant morbidity and mortality still occur in infants with congenital diaphragmatic hernia $(C D H)$, as a result of persistent fetal circulation due to pulmonary hypoplasia and pulmonary hypertension. The prognosis is predicted based on lung size (2DUS lung-to-head ratio or 3DUS lung volumetry), liver herniation, pulmonary circulation, and stomach position. Conventional 2DUS may not always be able to discriminate whether the liver is "up" or "down." Three-dimensional sonoangiography can help demonstrate subtle liver herniation by visualizing the hepatic vessels ascending through a small defect at the diaphragm, as shown in Fig. 5. Prenatal assessment of the pulmonary vasculature with high-definition Doppler interrogation (Fig. 6) may predict pulmonary hypertension [5]. Lung hypoplasia can also occur in a fetus with lower urinary tract obstruction (LUTO). Posterior urethral valve (PUV) is a common pathology found in cases of congenital LUTO; and is amenable for in utero surgery

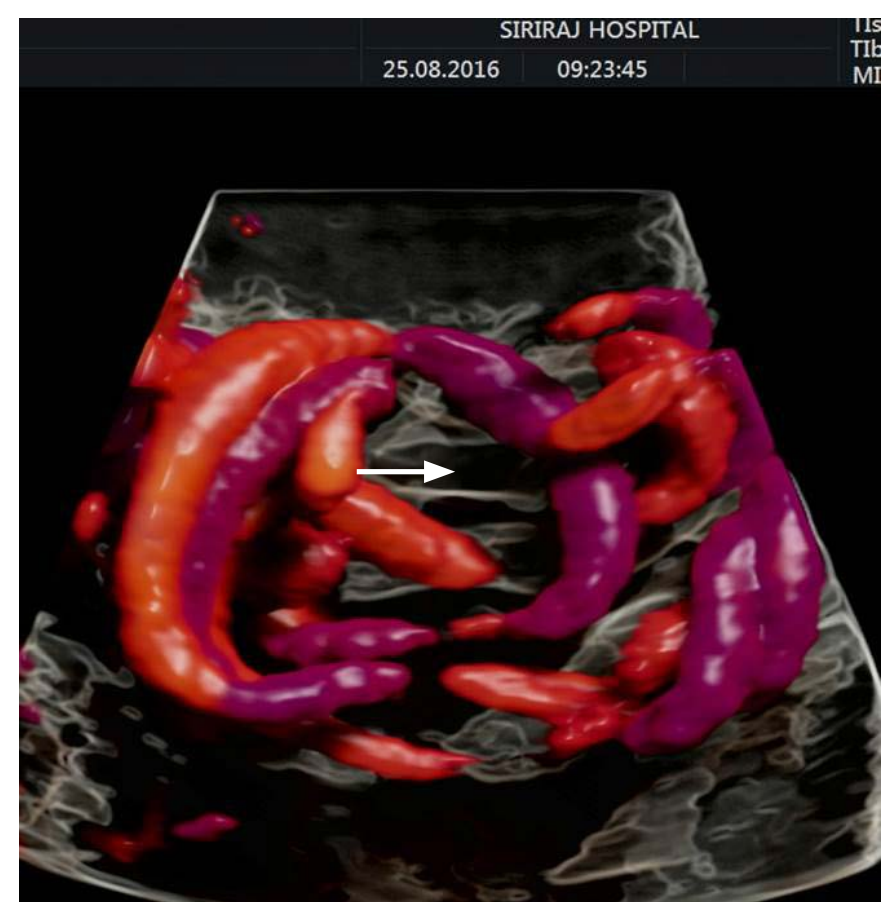

Fig. 4. Silhouette 3-dimensional sonoangiogram showing entanglement of the umbilical cords. This was a case of monoamniotic twins at 20 weeks of gestation with single fetal demise. Silhouette ultrasound enhanced the outline of the umbilical cord without blood flow (arrow), which belonged to the demised fetus.

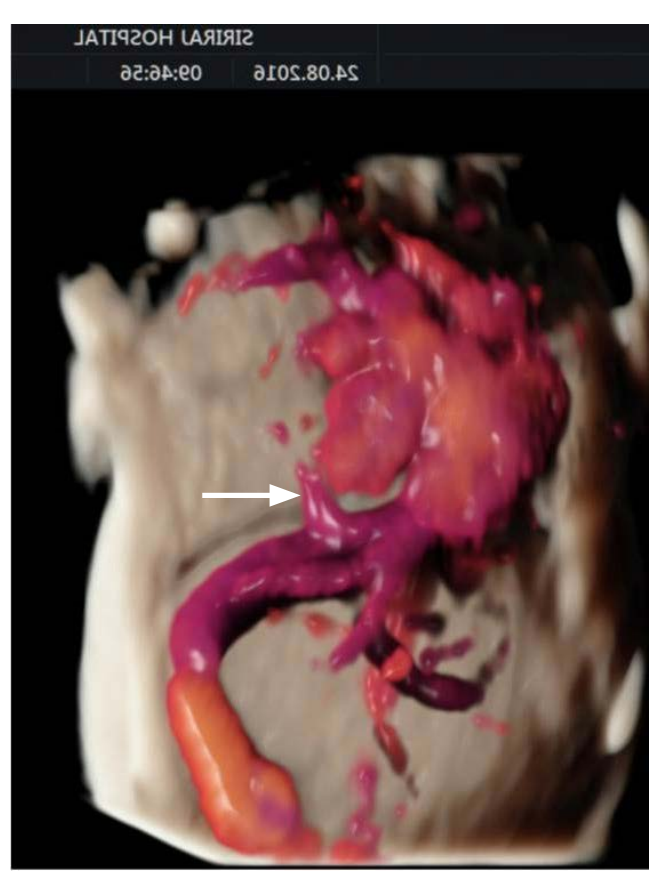

Fig. 5. Silhouette 3-dimensional sonoangiogram showing hepatic vessels ascending through a small defect at the diaphragm (arrow). This was a case of a fetus at 26 weeks with a subtle "liverup" right-sided congenital diaphragmatic hernia. Because B-mode ultrasound may not differentiate the echogenicity between the liver and lung of the fetus, the use of color Doppler sonoangiography may help reveal evidence of the liver being in the chest.

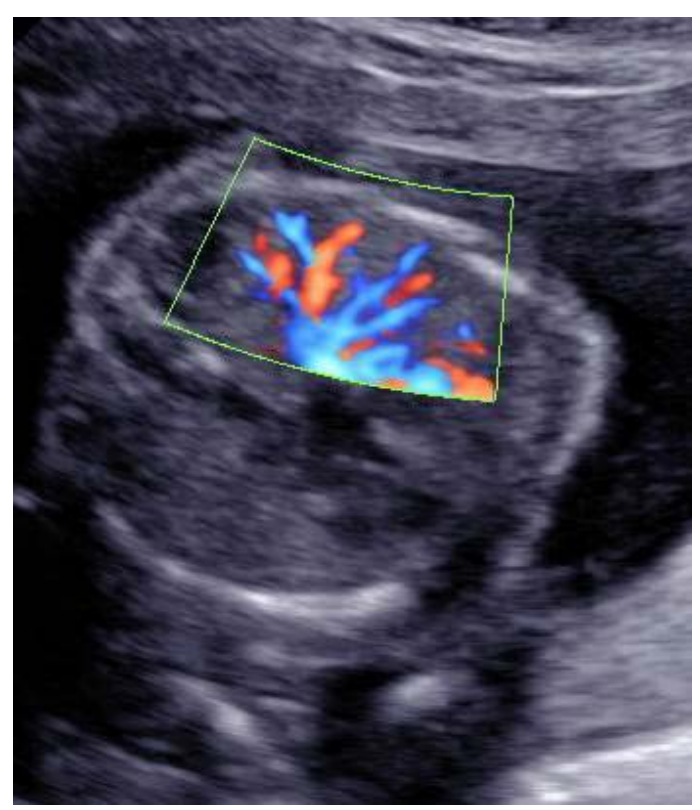

Fig. 6. High-definition color Doppler ultrasound showing normal fetal pulmonary vasculature. This was a case of a normal fetus at 20 weeks. Prenatal color Doppler imaging of the pulmonary arteries in fetuses with a congenital diaphragmatic hernia may predict perinatal outcomes. 
[6]. Prenatal ultrasound of PUV shows a dilated urinary bladder (megacystis) and proximal urethra. The hypertrophic detrusor muscle in a fetus with LUTO can be visualized as increased trabeculation of the internal surface of the urinary bladder in high-definition 3DUS surface-rendered mode, so-called virtual fetal cystoscopy (Fig. 7). Three-dimensional ultrasound with inversion mode enhancement (Fig. 8) can guide in utero access (antegrade fetal cystostomy) and laser fulguration of the PUV. In addition to biochemical assessments of fetal urine, the ultrasound appearance of fetal kidneys may predict in utero renal damage and dialysis dependence in childhood [7].

\section{Advancements in Ultrasound for Image-Guided Percutaneous Fetal Access}

Ultrasound guidance has been used to maintain the visibility of medical devices in minimally invasive in utero interventions for over 3 decades [8]. Visualization of the needle tip is important, especially for procedures that demand very high precision, such as percutaneous cardiac valvulotomy for fetuses with critical aortic or pulmonic stenosis [9]. The efficient use of fetal echocardiography not only allows the early detection of congenital heart disease and its often irreversible complications, but also enables balloon dilatation of severely stenotic or atretic valves in fetuses as early as 23 weeks of gestation. Progressive refinements in imaging, equipment, and biodegradable tissue regeneration materials will lead to better results of fetal valve interventions, in addition to their technical success [10].

Intraoperative real-time needle guidance with 2DUS is useful for complex procedures where direct visualization is suboptimal, such as in utero interventions. The most common site for in utero needle drainage is the amniotic cavity. There are two scanning planes over which returning echoes are obtained, as shown in Fig. 9. With the in-plane (or long access) approach, the needle enters the skin at the side of the probe. The needle traverses the plane of the ultrasound imaging and the whole shaft is visualized as it progresses towards the target. With the out-of-plane approach, the needle enters the skin away from the probe, and is aimed at the plane of the sound

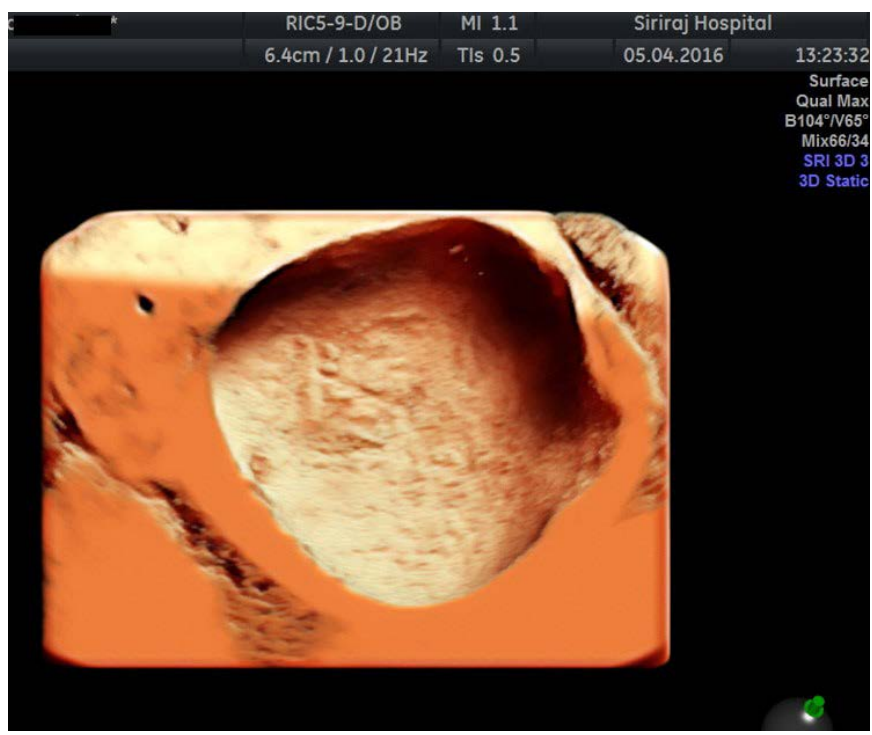

Fig. 7. High-definition surface-rendered 3-dimensional ultrasound of fetal urinary bladder (virtual fetal cystoscopy). This was a case of a fetus at 24 weeks with posterior urethral valve. The hypertrophic bladder trabeculations were a result of prolonged obstruction.

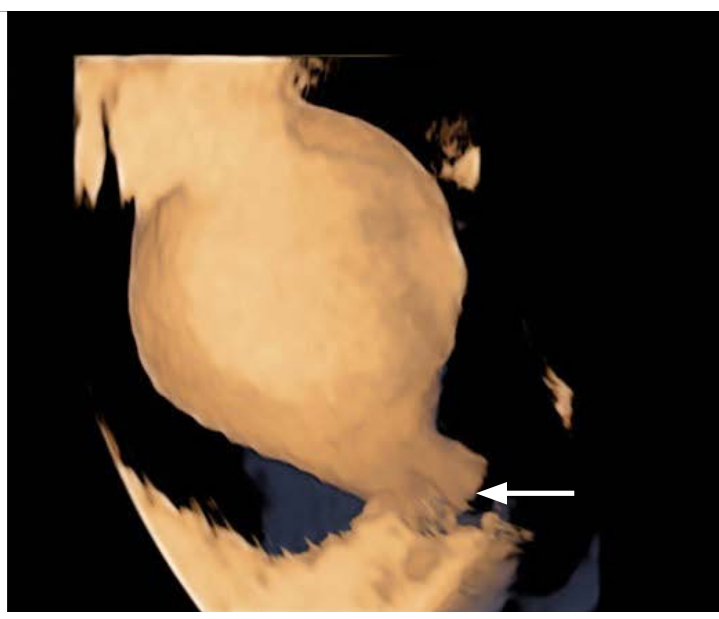

B

Fig. 8. Dilatation of urinary bladder and proximal urethra demonstrated with B-mode (A) and inversion mode of 3-dimensional ultrasonography (B) (arrows).

This was a case of a fetus at 24 weeks with posterior urethral valve. 

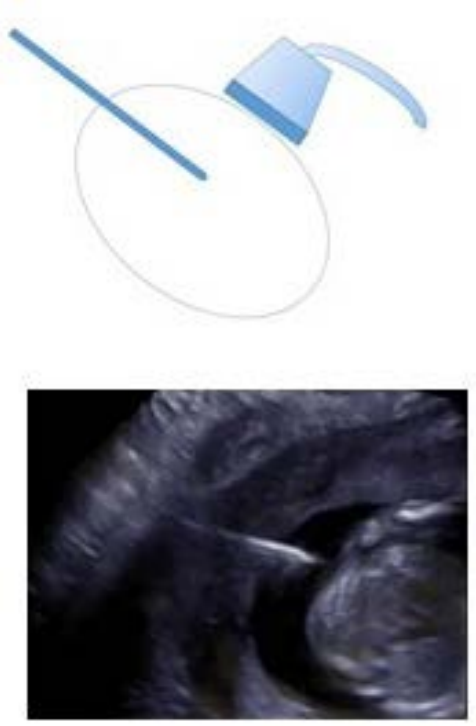

A

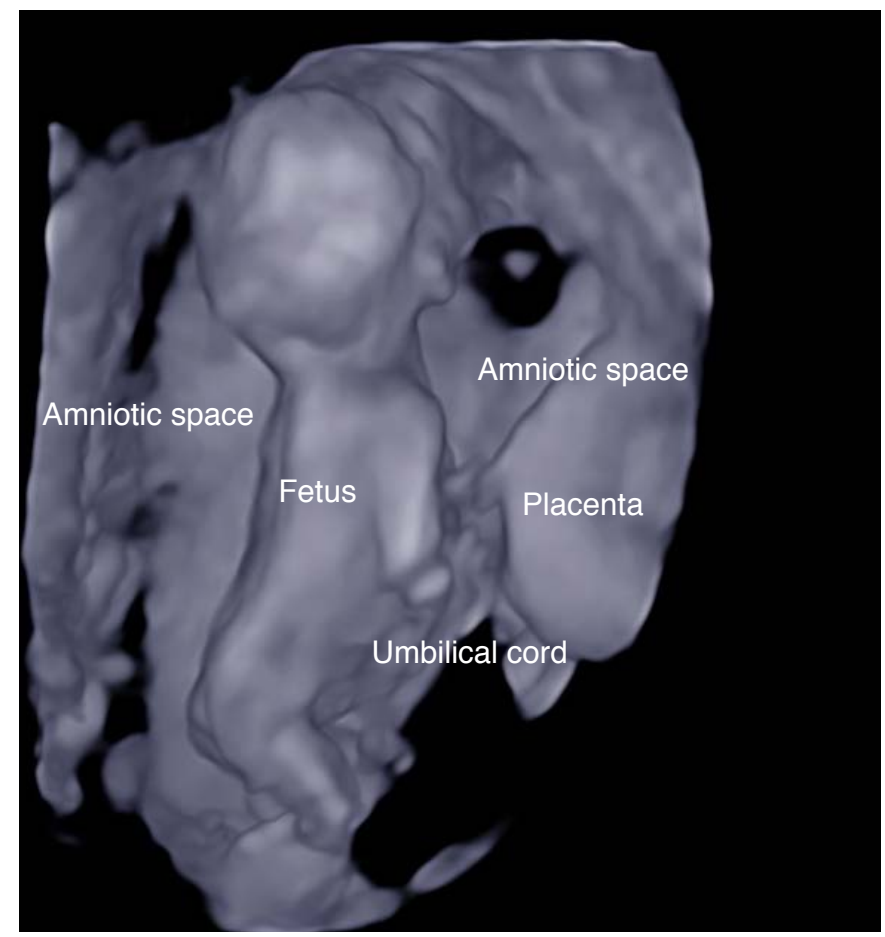

Fig. 10. Surface-rendered 3-dimensional ultrasonography showing close proximity of the fetus, umbilical cord, and placenta. Small unintentional lateralization of needles/shunts from the plane as they are inserted can potentially injure these structures.

waves. With this approach, just the needle tip is visualized and the remainder of the needle is off-screen. Although both are viable options, the in-plane approach is presented in the examples, as it shows a larger needle artifact that is easier to track.
Both the in-plane and out-of-plane approaches incur a risk of accidentally damaging structures not visible on the ultrasound screen, because the fetus, placenta, and umbilical cord are in close proximity, as shown in Fig. 10. Small unintentional movements or the deviation of needles/shunts from the plane as they are inserted can potentially lead to injury and loss of pregnancy. Needle guidance systems are commercially available. Guidance systems may be suitable for teaching new procedures, because they improve needle visibility and reduce the incidence of common complications [11]. However, in cases involving small target regions, such as in oligohydramnios, conventional 2DUS imaging may not be adequate for correct positioning of the needle.

Real-time 3DUS (also known as 4DUS) guidance has a theoretical advantage over 2DUS for aiding in surgical tasks, because the true position of the needle is determined in three orthogonal planes $[12,13]$. The addition of coronal and axial plane views may allow for an exact correlation between the needle position and the target site. Theoretically, needle placement using 4DUS is accurate regardless of the size of the target area; since the additional coronal and axial plane views allow an exact understanding of the relationship between the needle and the target site. Hence, the number of complications associated with difficult cases may be reduced. In a feasibility study, real-time 4DUS needle guidance technique was successfully used to perform amniocentesis, CVS, cordocentesis, and intrauterine transfusion. The 4DUS system appeared to contribute to the accuracy of needle placement by eliminating the lateralization phenomenon when a fixed needleguide attachment was used (for CVS and cordocentesis). The needle 


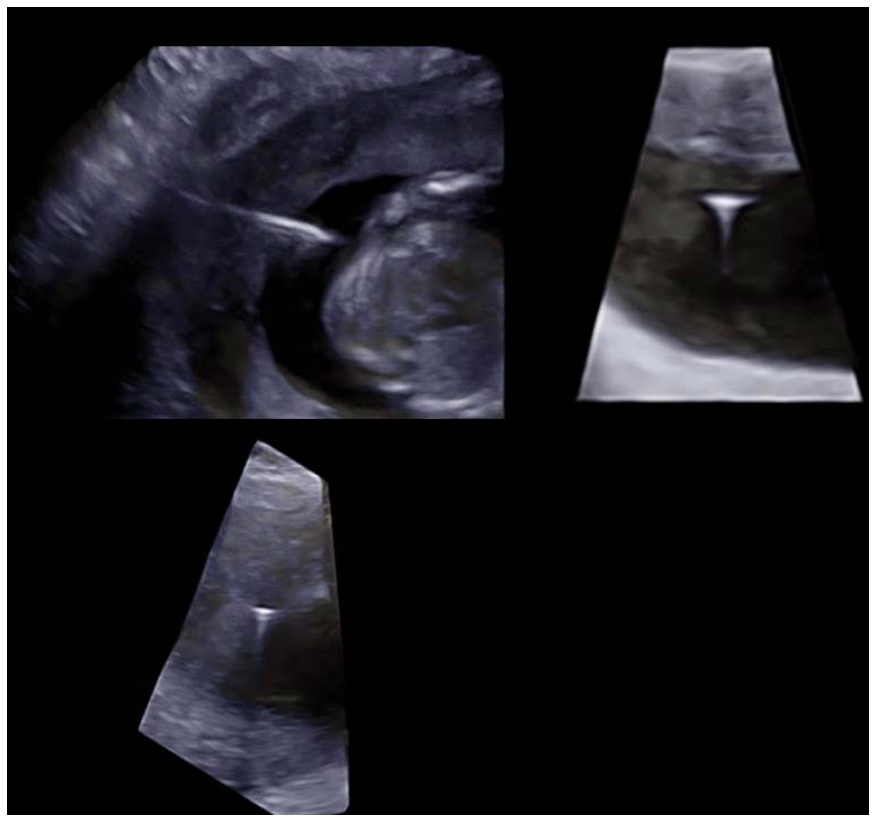

Fig. 11. Real-time 3-dimensional ultrasound multiplanar display during genetic amniocentesis. The tip of a 20-gauge amniocentesis needle approaching the target area can be simultaneously seen from plane $X, Y$, and $Z$, respectively. This orthogonal view could provide complete optimization of both the imaging angle and insertion path.

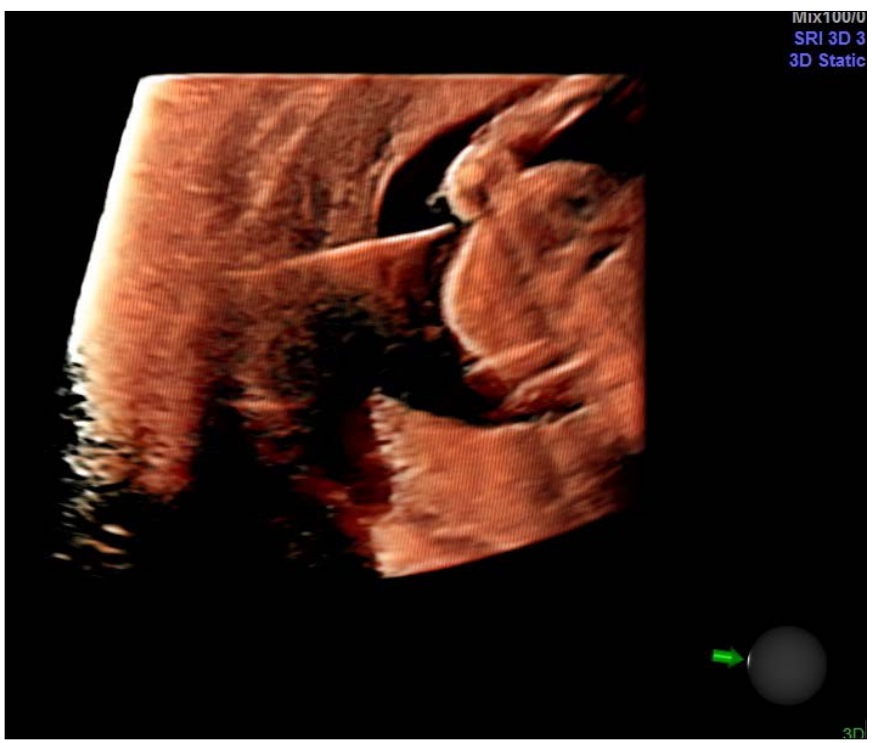

Fig. 12. Real-time 3-dimensional ultrasound monitoring of the tip of a 20-gauge amniocentesis needle showing the conventional 'in-plane' approach. The needle tip and shaft are simultaneously visualized.

tip was visualized in each orthogonal plane in most freehand 4DUSguided amniocentesis cases (Figs. 11, 12) [14]. However, 4DUS guidance for transcervical CVS comes at the expense of a prolonged procedure time in comparison to 2DUS guidance [15]. Although

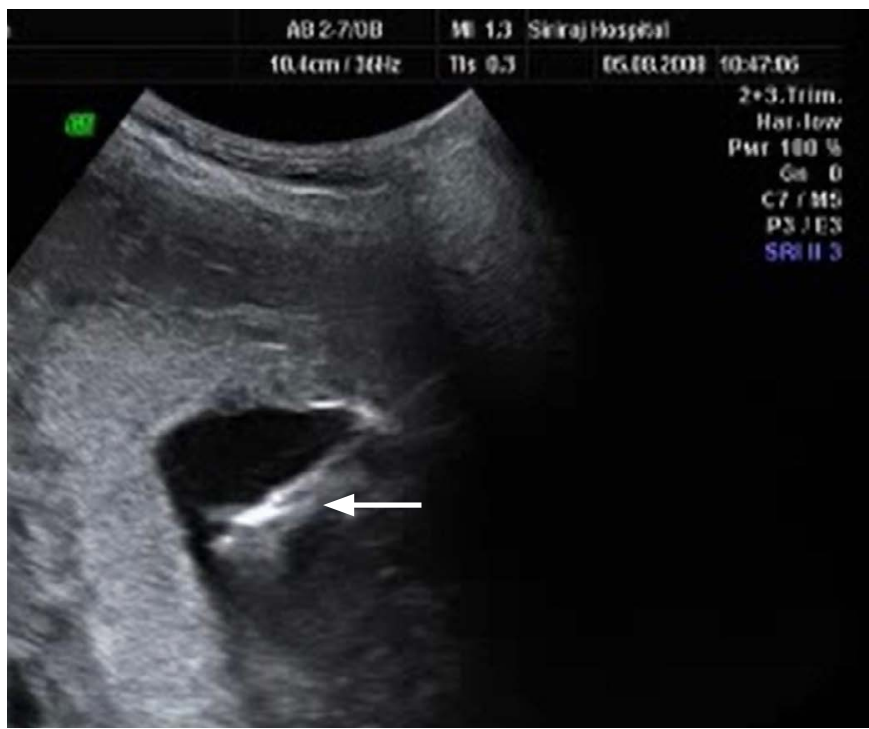

Fig. 13. Intraoperative B-mode ultrasound monitoring of the tip of bipolar forceps during umbilical cord diathermy. This was a case of selective fetal growth restriction type II (reversed end-diastolic flow in the umbilical artery of the twin with growth restriction) in monochorionic 20-week twins undergoing umbilical cord occlusion for the purpose of selective termination. The umbilical cord to be treated was placed between 2 condenser plates (arrow), so that the highest temperature would be concentrated.

4DUS provided reassurance that no fetal parts were in the needle path, the technology did not offer any other advantages over 2DUS. This new modality has not yet proved effective in reducing the number of needle insertions [16]. The value of 4DUS guidance for less-experienced operators remains to be determined. Future developments in 4DUS technology may refine the utility of this technique for invasive obstetric procedures.

The operator's experience remains crucial for adequate visualization of the needle tip. A variety of technologies, ranging from simple mechanical devices to advanced automated needledetection software, may improve the alignment of the needle and the ultrasound beam to facilitate a clear view of the needle tip. As many of these new techniques were originally developed for other purposes, such as liver or breast biopsy, perinatologists might not be familiar with them. Experiments have been conducted with additional strategies to improve needle tracking, including (1) using 3D instead of 2D ultrasound, (2) Golay coding to increase the signal-to-noise ratio, and (3) the use of a higher-dimensional array ultrasound transducer to improve spatial resolution. Although 1.25D arrays have been commercially available for several years, a recent study showed that 1.5D transducer elements were also feasible for needle tracking in an in vivo pregnant sheep model [17]. Newlydeveloped instruments and novel scanning modes must be feasible 
in clinically realistic environments.

\section{Ultrasound Monitoring during Fetal Surgery}

Ultrasound is an integral part of all kinds of in utero interventions, even open fetal surgery. For instance, in the open surgical repair of myelomeningocele (MMC), the fetus and placenta are located by ultrasound, so that the hysterotomy location can be chosen safely. The fetus is visualized by ultrasound and manually positioned within the uterus such that the MMC sac is in the center of the hysterotomy. In patients with an anterior placenta, hysterotomy is either fundal or posterior. Some authors have suggested the use of intermittent umbilical artery Doppler ultrasonography during open fetal surgery, but the short-term impact of absent/reversed enddiastolic flow on fetal well-being remains elusive [18].

The surgical interruption of blood flow to the acardiac twin aims at maintaining the viability of the other (donor or pump) twin, especially in the presence of hydrops. Umbilical cord occlusion can be performed with bipolar diathermy (Fig. 13), and ablation of intrafetal blood vessels can be performed with either laser (Fig. 14) or radiofrequency ablation (Fig. 15) [19]. Real-time monitoring of the interstitial thermal effects during in utero vascular ablation is important to prevent inadvertent injury of the co-twin. The growing

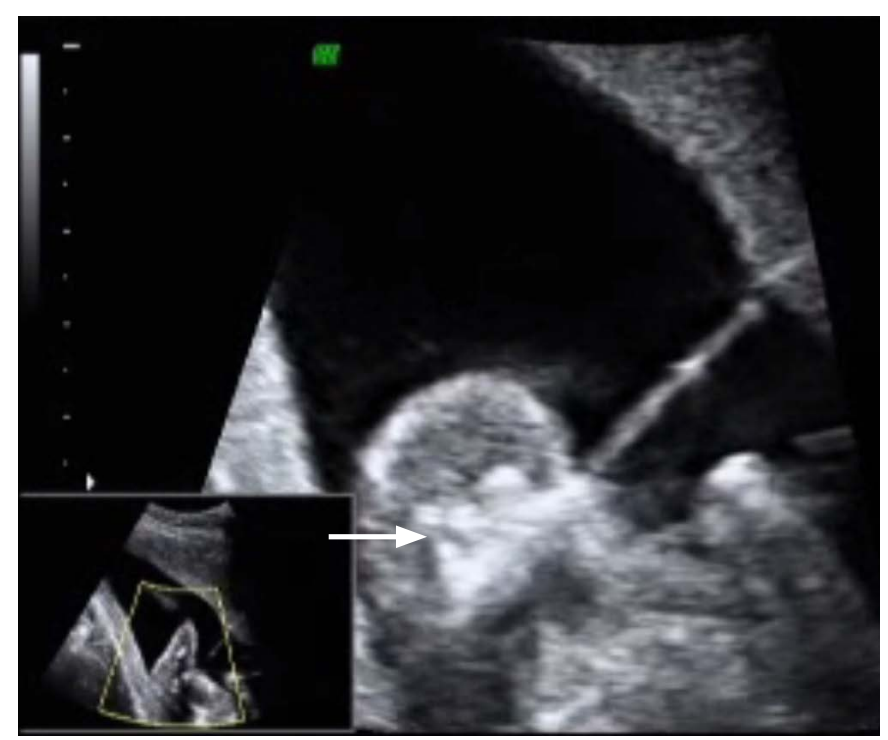

Fig. 14. Intraoperative B-mode ultrasound monitoring of the tip of the laser fiber during intrafetal laser ablation. This was a case of an anomalous fetus at 14 weeks in monoamniotic twins with umbilical cord entanglement. A 400-micron neodymium-doped yttrium aluminum garnet laser fiber was threaded through an 18-gauge needle during the ablation of blood vessels within this fetus for the purpose of selective feticide. Note the echogenic flare at the tip (arrow) during laser firing. availability of video endoscopic surgery and the miniaturization of cameras and fiber endoscopes have shifted the pendulum to lessinvasive endoscopic fetal surgery; hence, the need for high-quality intraoperative ultrasonography is growing.

\section{Advancements in Purpose-Designed Instruments Complimentary to Prenatal Ultrasound}

\section{Needle: Novel Designs}

Lancet-point needles are commonly used for transabdominal CVS and genetic amniocentesis [20]. A purpose-designed amniocentesis needle, with enhancement of the needle tip under ultrasound, is commercially available (EchoTip, Bloomington, IN, USA). A needle tracking system with a fiber-optic transmitter has been developed and shown to be feasible in a fetal sheep model. A custom elastomeric nanocomposite is coated on the distal end of an optical fiber, which is positioned within the lumen of a commercial 22-gauge needle. The delivery of pulsed light to the coating results in the photoacoustic generation of ultrasonic waves, which are received by an external ultrasound imaging probe [21].

\section{Shunt: Novel Designs}

In utero shunting provides a longer drainage, which may be suitable in cases of recurrent fluid accumulation in the fetal body cavity. The most common indications for fetal shunting procedures are massive pleural effusion, macrocystic congenital pulmonary airway malformation, and LUTO. The Rodeck rocket shunt (Rocket Medical

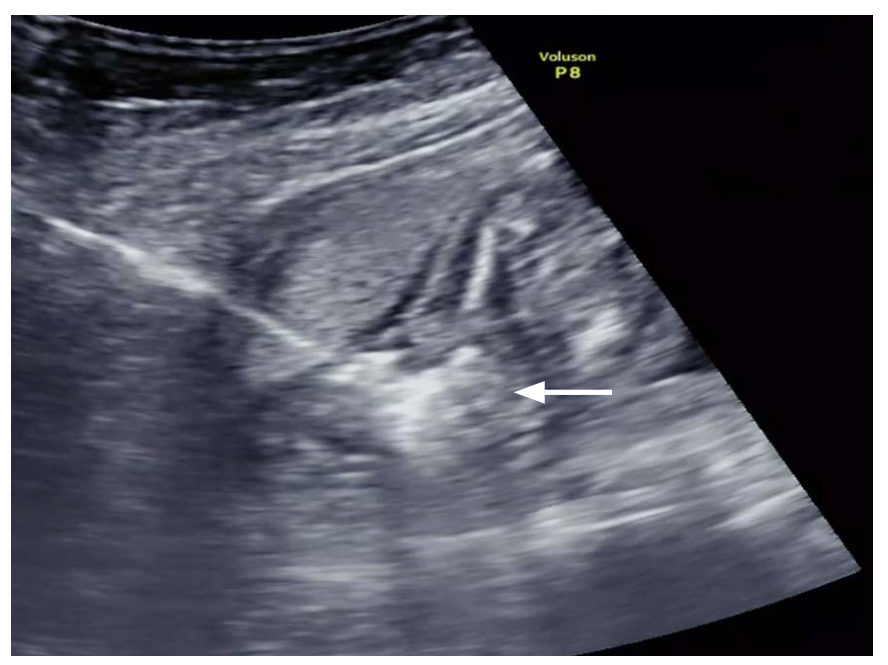

Fig. 15. Intraoperative B-mode ultrasound monitoring of radiofrequency ablation during ablation. This was a case of a 20-week-old acardiac fetus undergoing selective termination. Note the spherical tissue coagulation (arrow) around the radiofrequency tines while the blood vessels were being ablated. 
PLC, Washington, UK), Harrison bladder shunt (Cook Medical, Spencer, IN, USA), and double-basket catheter (Hakko Co, Nagano, Japan) are applied with a technique similar to the Seldinger technique [22]. Surface-rendered 3DUS can demonstrate a global view of the shunt in relation with the fetal anatomy, as shown in Fig. 16. Shunt dislodgement is not uncommon. A new shunting device, combining the standard double pig-tail catheter with an atrial septal occluder device (AGA Medical, Plymouth, MN, USA), which is dislodgement-proof, has been developed for the in utero treatment of LUTO [23]. The retrieval and replacement of a dislodged shunt is feasible with a novel approach utilizing small grasping forceps (3 $\mathrm{mm}$ ) under continuous ultrasound guidance [24].

\section{Video Endoscopic-Assisted Surgery (Fetoscopy)}

The current practice of minimally invasive in utero surgery involves the coordinated use of ultrasound image guidance to provide a global navigational view; the so-called picture-in-picture view is demonstrated in Fig. 17. Fetoscopic procedures, such as laser photocoagulation of chorionic anastomoses in TTTS, fetal endotracheal occlusion in $\mathrm{CDH}$, and in utero laser ablation of PUV are examples of the combined benefits of direct visualization and small access. However, it is difficult to register two sources of images intuitively. Under ultrasound guidance, a trocar or cannula can be inserted under direct visualization or by the Seldinger

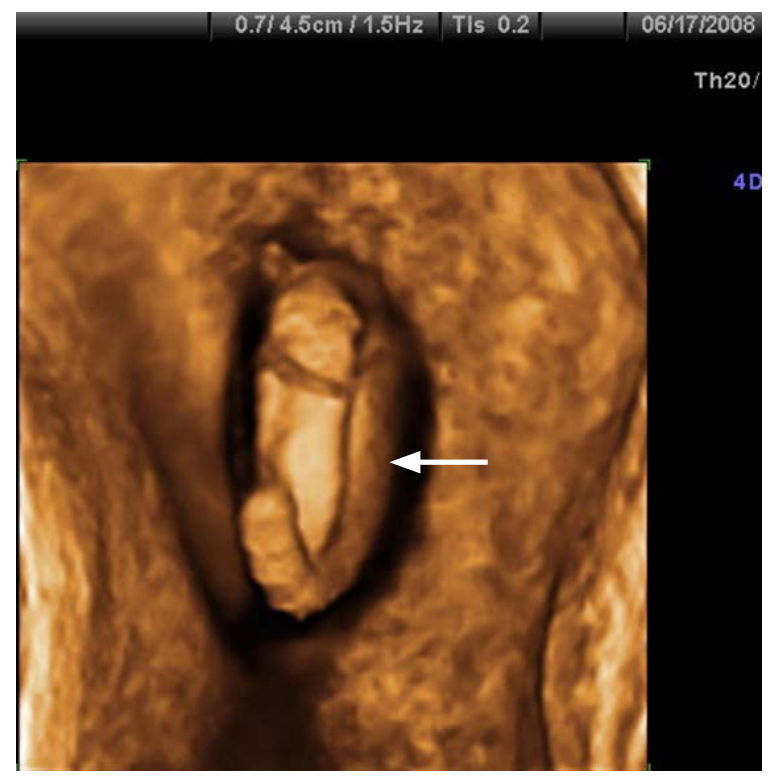

Fig. 16. Surface-rendered 3-dimensional ultrasonography showing a Harrison bladder shunt in situ. This was a case of a fetus with posterior urethral valve at 24 weeks undergoing in utero vesicoamniotic shunting. Note that the coil of the Harrison bladder shunt (arrow) was lying flat on the fetal abdominal surface, which ensured that this diversion device was working properly. technique. Once the amniotic cavity is safely accessed, the trocar is replaced by the fetoscope. Pathologic chorionic anastomoses are coagulated under direct visualization. When adequately performed, laser surgery can prevent prenatal loss or neurological impairment from TTTS. The success of this procedure depends on the dexterous, visual, and perceptual constraints associated with this minimally invasive mode of operation that uses a narrow-diameter fetoscope at close proximity, hence displaying only a small portion of the vast vasculature of the placenta. An integrated surgical navigation system equips surgeons with visual and perceptual guidance to perform the procedure. A novel 3DUS image mapping approach that can provide a dynamically expanding panoramic view of the vast vasculature network of the placenta is being developed [25].

Computer-assisted surgical planning using 3D virtual models may improve the surgeon's understanding of a patient's complex anatomy, and hence may be a powerful tool in surgical planning and intraoperative guidance. Indications from other specialties suggest that surgical planning and guidance will be useful for improving outcomes [26].

\section{High-Intensity Focused Ultrasound}

High-intensity focused ultrasound (HIFU) collects ultrasonic energy within millimeters and increases tissue temperature nearinstantaneously, thereby causing tissue degeneration and thermal

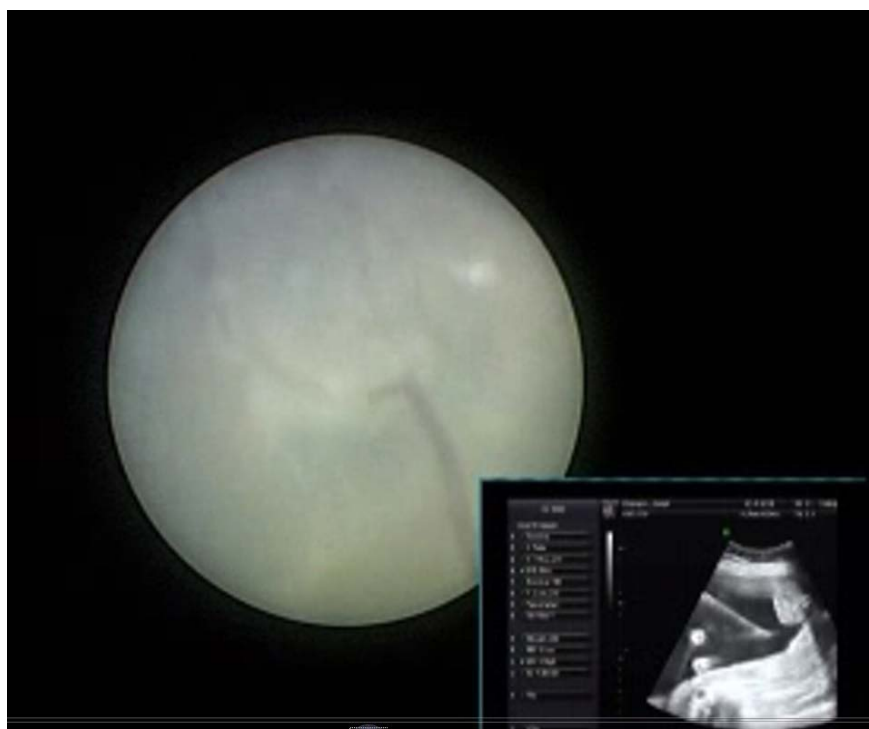

Fig. 17. Picture-in-picture system simultaneously projecting outputs from endoscopic (fetoscopic) and sonographic views on the same screen. A high-quality compact ultrasound system was integrated with video endoscopy (fetoscopy) at a single workstation. High-resolution ultrasound and an endoscopic image were displayed simultaneously, promoting clear visualization for in utero procedures that require high precision. 


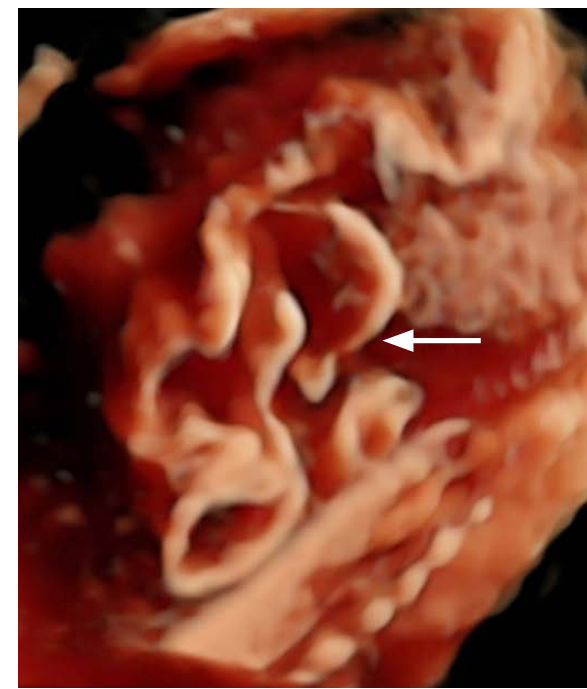

A

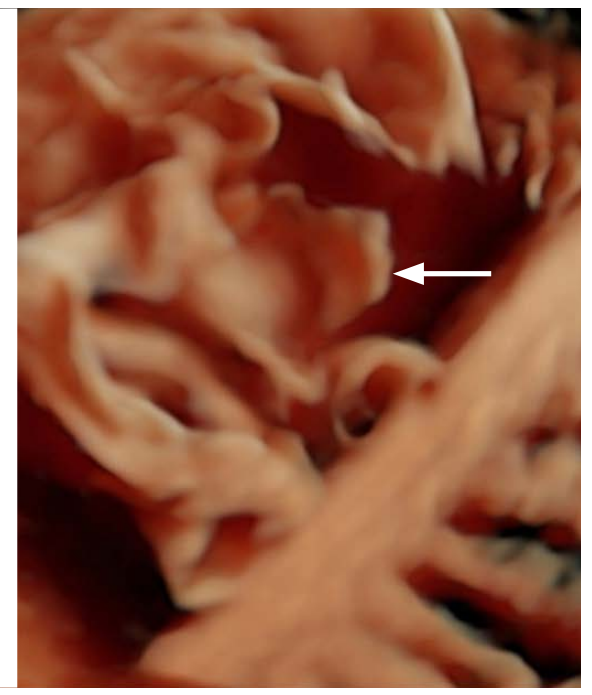

B

Fig. 18. High-definition, surface-rendered 3-dimensional ultrasonography showing loose-end sheets of perforated intertwin amniotic membranes (arrows).

This was a case of monochorionic diamniotic twins at 21 weeks with iatrogenic septostomy after laser surgery for twinto-twin transfusion syndrome. These constrictive bands ( $A$ and $B$ ) could entangle fetal parts, causing amniotic band sequence.

denaturation of fetal blood vessels without direct fetal contact [27]. The initial human experiences of HIFU for non-invasive blood flow occlusion in patients with TRAP sequence were reported starting in 2013 [28]. This approach is still experimental because (1) the ultrasound intensity necessary for vascular occlusion may differ between animal experiments and clinical applications in humans due to problems such as attenuation of ultrasonic waves, and (2) the appropriate ultrasound intensity remains elusive.

\section{Prenatal Detection of Procedure-Related Complications with Ultrasound}

The perinatal outcomes of laser surgery for TTTS are still far from ideal [19]. There are procedure-related complications, such as iatrogenic preterm rupture of membranes and extremely premature delivery, iatrogenic septostomy, twin anemia-polycythemia sequence, and recurrence of TTTS [29-31]. Surface-rendered high-definition 3DUS can demonstrate iatrogenic septostomy (Fig. 18). These constriction bands may lead to amniotic band sequence (Fig. 19).

\section{Potential Risks of Prenatal Ultrasound}

Although there have been no reported incidents of harm to human fetuses in over 40 years of extensive use of medically indicated and supervised diagnostic ultrasound, the International Society of Ultrasound in Obstetrics and Gynecology and the World Federation of Ultrasound in Medicine and Biology disapprove of the nonindicated use of ultrasonography for the sole purpose of providing souvenir images of a fetus [32]. It is of the utmost importance not to expose the embryo and fetus to undue harm from ultrasound-

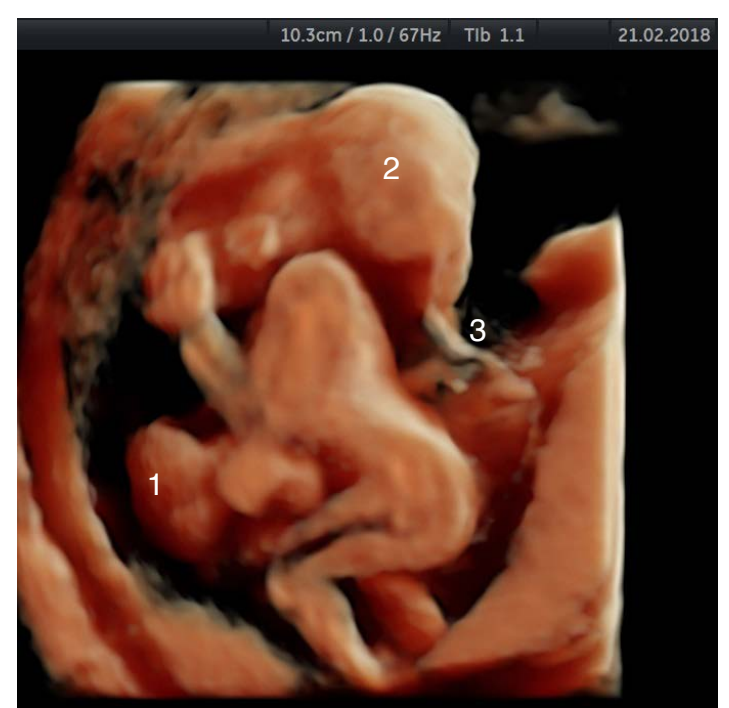

Fig. 19. High-definition, surface-rendered 3-dimensional ultrasonography showing amniotic band sequence in a 17-week-old fetus. Note the acquired ventral wall defect (1) and encephalocele (2) caused by entrapment in fibrous constriction (amniotic) bands (3) while in utero.

related thermal energy and neuronal apoptosis, particularly in the earliest stages of pregnancy and when more advanced sonographic modalities (i.e., Doppler studies and 3DUS) are used [33]. At these stages, Doppler recording, when clinically indicated, should be performed at the lowest possible energy levels, with the displayed thermal index $\leq 1.0$ and an exposure time preferably no longer than 5-10 minutes for each interrogation. The total exposure is strictly not exceeding 60 minutes [32]. 


\section{Conclusion}

For fetal interventions, image guidance with B-mode ultrasonography remains indispensable. Doing so requires knowledge of the fundamental aspects of the basic ultrasound physics, interactions of ultrasound with tissues and medical devices, ultrasound pulse formation, scanning of the ultrasound beam, and echo detection and signal processing. Novel ultrasound technologies for in utero interventions are continuously reported and tested. It is expected that perinatal outcomes will improve as experience with these techniques accumulates. A fetoscopy simulator has been developed to enhance bench training [34]. Recent technical innovations that have been developed to improve the performance of modern ultrasound equipment include tissue harmonic imaging, spatial compound imaging, extended field of view imaging, coded pulse excitation, electronic section focusing, 3DUS and 4DUS imaging, and the general trend toward equipment miniaturization. Continuous evolution in the capabilities of ultrasound will lead to even more exciting developments on the horizon.

ORCID: Nisarat Phithakwatchara: http://orcid.org/0000-0002-2517-4432; Tuangsit Wataganara: http://orcid.org/0000-0001-7172-053X

\section{Conflict of Interest}

No potential conflict of interest relevant to this article was reported.

\section{Acknowledgments}

The authors would like to thank Chutima Yaiyiam for her administrative assistance.

\section{References}

1. Phithakwatchara N, Nawapun K, Panchalee T, Viboonchart S, Mongkolchat N, Wataganara T. Current strategy of fetal therapy I: Principles of in-utero treatment, pharmacologic intervention, stem cell transplantation and gene therapy. J Fetal Med 2017;4:131138.

2. Wataganara $T$, Sutanthaviboon A, Ngerncham S, Vantanasiri C. Three-dimensional power Doppler in the diagnosis and surgical management of thoraco-omphalopagus conjoined twins. Ultrasound Obstet Gynecol 2008;32:236-237.

3. Wataganara $T$, Ruangvutilert $P$, Sunsaneevithayakul $P$, Russameecharoen K, Nawapun K, Phithakwatchara N. Threedimensional ultrasound for prenatal assessment of conjoined twins: additional advantages? J Perinat Med 2017;45:667-691.

4. Ruiz-Cordero R, Birusingh RJ, Pelaez L, Azouz M, Rodriguez MM. Twin reversed arterial perfusion sequence (TRAPS): an illustrative series of 13 cases. Fetal Pediatr Pathol 2016;35:63-80.

5. Ruano R, Takashi E, da Silva MM, Campos JA, Tannuri U, Zugaib M. Prediction and probability of neonatal outcome in isolated congenital diaphragmatic hernia using multiple ultrasound parameters. Ultrasound Obstet Gynecol 2012;39:42-49.

6. Farrugia MK, Braun MC, Peters CA, Ruano R, Herndon CD. Report on The Society for Fetal Urology panel discussion on the selection criteria and intervention for fetal bladder outlet obstruction. J Pediatr Urol 2017;13:345-351.

7. Vanderheyden T, Kumar S, Fisk NM. Fetal renal impairment. Semin Neonatol 2003;8:279-289.

8. Carpenter RJ Jr, Hinkley CM, Carpenter AF. Midtrimester genetic amniocentesis: use of ultrasound direction vs. blind needle insertion. J Reprod Med 1983;28:35-40.

9. Gardiner HM. In-utero intervention for severe congenital heart disease. Best Pract Res Clin Obstet Gynaecol 2008;22:49-61.

10. Sizarov A, Boudjemline Y. Valve interventions in utero: understanding the timing, indications, and approaches. Can J Cardiol 2017;33:1150-1158.

11. Paltieli Y, Degani S, Zrayek A, Gonen R, Lewinski MR, Zamberg Y, et al. A new guidance system for freehand, obstetric ultrasoundguided procedures. Ultrasound Obstet Gynecol 2002;19:269-273.

12. Cannon JW, Stoll JA, Salgo IS, Knowles HB, Howe RD, Dupont PE, et al. Real-time three-dimensional ultrasound for guiding surgical tasks. Comput Aided Surg 2003;8:82-90.

13. Kim SR, Won HS, Lee PR, Kim A. Four-dimensional ultrasound guidance of prenatal invasive procedures. Ultrasound Obstet Gynecol 2005;26:663-665.

14. Dolkart L, Harter M, Snyder M. Four-dimensional ultrasonographic guidance for invasive obstetric procedures. J Ultrasound Med 2005;24:1261-1266.

15. Adeniji B, Williams J 3rd, Solt I, Morales C, Alanakian A, Rotmensch S. Clinical trial of multiplanar real-time 4- versus 2-dimensional sonographic guidance for transcervical chorionic villus sampling. J Ultrasound Med 2011;30:309-312.

16. Tonni G, Centini G, Rosignoli L, Argento C, Centini G. 4D vs 2D ultrasound-guided amniocentesis. J Clin Ultrasound 2009;37:431435.

17. Xia W, West SJ, Mari JM, Ourselin S, David AL, Desjardins AE. 3D ultrasonic needle tracking with a 1.5D transducer array for guidance of fetal interventions. Med Image Comput Comput Assist Interv 2016;9900:353-361.

18. Sinskey JL, Rollins MD, Whitlock E, Moon-Grady AJ, Vu L, Feiner $J R$, et al. Incidence and management of umbilical artery flow abnormalities during open fetal surgery. Fetal Diagn Ther 2018;43:274-283.

19. Nawapun K, Phithakwatchara N, Panchalee T, Viboonchart S, Mongkolchat N, Wataganara T. Current strategy of fetal therapy II: Invasive fetal interventions. J Fetal Med 2017;4:139-148. 
20. Wax JR, Cartin A, Chard R, Carpenter M, Pinette MG. First trimester transabdominal chorionic villus sampling: does the needle matter? J Clin Ultrasound 2012;40:385-388.

21. Xia W, Noimark S, Ourselin S, West SJ, Finlay MC, David AL, et al. Ultrasonic needle tracking with a fibre-optic ultrasound transmitter for guidance of minimally invasive fetal surgery. Med Image Comput Comput Assist Interv 2017; 10434:637-645.

22. Seldinger SI. Catheter replacement of the needle in percutaneous arteriography: a new technique. Acta Radiol 1953;39:368-376.

23. Quintero RA, Gomez Castro LA, Bermudez C, Chmait RH, Kontopoulos EV. In utero management of fetal lower urinary tract obstruction with a novel shunt: a landmark development in fetal therapy. J Matern Fetal Neonatal Med 2010;23:806-812.

24. Adams TM, Kunzier NB, Chavez MR, Vintzileos AM. Ultrasoundguided retrieval and position replacement of a dislodged fetal pleuro-amniotic shunt: a novel approach for a known complication of feto-amniotic shunting. Fetal Diagn Ther 2016;39:78-80.

25. Yang L, Wang J, Ando T, Kubota A, Yamashita H, Sakuma I, et al. Self-contained image mapping of placental vasculature in 3D ultrasound-guided fetoscopy. Surg Endosc 2016;30:4136-4149.

26. Pratt R, Deprest J, Vercauteren T, Ourselin S, David AL. Computerassisted surgical planning and intraoperative guidance in fetal surgery: a systematic review. Prenat Diagn 2015;35:1159-1166.

27. Ichizuka K, Matsuoka R, Aoki H, Hasegawa J, Okai T, Umemura S. Basic study of less invasive high-intensity focused ultrasound (HIFU) in fetal therapy for twin reversed arterial perfusion (TRAP) sequence. J Med Ultrason (2001) 2016;43:487-492.
28. Okai T, Ichizuka K, Hasegawa J, Matsuoka R, Nakamura M, Shimodaira $K$, et al. First successful case of non-invasive inutero treatment of twin reversed arterial perfusion sequence by high-intensity focused ultrasound. Ultrasound Obstet Gynecol 2013;42:112-114.

29. Roberts D, Neilson JP, Kilby M, Gates S. Interventions for the treatment of twin-twin transfusion syndrome. Cochrane Database Syst Rev 2008;(1):CD002073.

30. Slaghekke F, Lopriore E, Lewi L, Middeldorp JM, van Zwet EW, Weingertner AS, et al. Fetoscopic laser coagulation of the vascular equator versus selective coagulation for twin-to-twin transfusion syndrome: an open-label randomised controlled trial. Lancet 2014;383:2144-2151.

31. Wataganara T, Chanprapaph P, Chuangsuwanich T, Kanokpongsakdi S, Chuenwattana P, Titapant V. Reverse twin-twin transfusion syndrome after fetoscopic laser photocoagulation of chorionic anastomoses: a case report. Fetal Diagn Ther 2009;26:111-114.

32. Salvesen K, Lees C, Abramowicz J, Brezinka C, Ter Haar G, Marsal K, et al. ISUOG statement on the safe use of Doppler in the 11 to 13 +6 -week fetal ultrasound examination. Ultrasound Obstet Gynecol 2011;37:628.

33. Pooh RK, Maeda K, Kurjak A, Sen C, Ebrashy A, Adra A, et al. 3D/4D sonography: any safety problem. J Perinat Med 2016;44:125-129.

34. Wataganara T. Development of fetoscopic and minimally invasive ultrasound-guided surgical simulator: part of global education. Donald School J Ultrasound Obstet Gynecol 2013;7:352-355. 